\title{
A INFLUÊNCIA DO AMBIENTE FAMILIAR E ESCOLAR NA AQUISIÇÃO E NO DESENVOLVIMENTO DA LINGUAGEM: REVISÃO DE LITERATURA
}

\section{Family and school environment influences on language acquisition and development: literature review}

\author{
Ramilla Recla Scopel (1), Valquíria Conceição Souza ${ }^{(2)}$, Stela Maris Aguiar Lemos ${ }^{(3)}$
}

\begin{abstract}
RESUMO
Tema: o termo linguagem é definido como organizado sistema de símbolos, com propriedades particulares que desempenham a função de codificação, estruturação e consolidação dos dados sensoriais, o que permite que experiências sejam comunicadas e seus conteúdos transmitidos. $O$ desenvolvimento da linguagem depende não somente das condições biológicas inatas de cada indivíduo, como também sofre influência de fatores ambientais presentes nos meios em que as crianças estão inseridas, como por exemplo, a família e a escola. Objetivo: descrever e analisar as produções científicas relevantes para o entendimento da influência do ambiente familiar e escolar na aquisição e desenvolvimento da linguagem em crianças por meio de revisão da literatura. Conclusão: as produções científicas apresentadas apontam a relevância da estimulação no âmbito familiar e escolaridade dos pais, porém pôde-se perceber a carência de estudos que relacionassem o desenvolvimento infantil com o ambiente escolar. Outro fator que chamou atenção foi a falta de estudos que correlacionem vocabulário e fonologia com os fatores ambientais escolares e familiares. A partir da revisão da literatura abrem-se novas perspectivas de trabalhos a serem realizados na Fonoaudiologia para que as lacunas existentes possam ser preenchidas com novos conhecimentos sobre desenvolvimento infantil.
\end{abstract}

DESCRITORES: Ambiente; Família; Linguagem; Fonoaudiologia; Creches; Desenvolvimento Infantil

\section{INTRODUÇÃO}

O termo linguagem pode ser definido como um organizado sistema de símbolos, com propriedades particulares que desempenham a função de codificação, estruturação e consolidação dos dados sensoriais, o que permite que experiências sejam comunicadas e seus conteúdos transmitidos. Deste modo, a linguagem pode ser definida como um sistema de troca de informações ${ }^{1}$.

(1) Acadêmica do curso de Fonoaudiologia da Universidade Federal de Minas Gerais.

(2) Acadêmica do curso de Fonoaudiologia da Universidade Federal de Minas Gerais.

(3) Fonoaudióloga; Professora Adjunto do Departamento de Fonoaudiologia da Universidade Federal de Minas Gerais; Doutora em Ciências pela Universidade Federal de São Paulo.

Conflito de interesses: inexistente
As diferentes línguas são compostas por fonemas distintos. A criança, durante o seu desenvolvimento, aprende a ignorar alguns fonemas e dirige a atenção aos mais utilizados em sua língua materna. As regras permitem ao sujeito fazer a distinção entre os diversos fonemas da língua considerando suas particularidades ${ }^{2}$. $\mathrm{Na}$ aquisição fonológica normal, o domínio do sistema fonológico da língua alvo é atingido espontaneamente, em uma sequência e faixa etária comum à maior parte das crianças (quatro a seis anos) ${ }^{3}$.

O desenvolvimento lexical mantém inter-relação com as experiências sociointeracionais da criança e essas experiências fornecem as formas lexicais convencionais adquiridas no início do desenvolvimento; contudo o crescimento do vocabulário depende da variação individual de cada pessoa ${ }^{4}$.

$O$ adequado desenvolvimento da linguagem verbal é de grande importância para o inicio do 
processo de alfabetização, contribuindo para que ocorra uma boa comunicação escrita. $O$ vocabulário e a fonologia adequados possibilitam um bom desempenho social da linguagem por meio de uma emissão eficiente e pronúncia correta ${ }^{2}$.

O desenvolvimento da linguagem depende não somente das condições biológicas inatas de cada indivíduo, como também sofre influência de fatores ambientais presentes nos meios em que as crianças estão inseridas, como por exemplo, a família e a escola ${ }^{5}$.

O meio assume um papel essencial no processo de aquisição e desenvolvimento da linguagem, pois nele a criança vai se desenvolver de forma progressiva. Em um ambiente estimulante e facilitador a complexidade da linguagem da criança ou de cada individuo se desenvolverá de forma natural respeitando o ritmo individual ${ }^{6}$.

A escola é um dos ambientes que proporcionam o processo do desenvolvimento infantil. Cabe às instituições criar condições que propiciem ao indivíduo uma aprendizagem contínua, em que os conhecimentos adquiridos nos os primeiros anos de vida possam ser explorados, confrontados e aprofundados na instituição escolar ${ }^{7}$.

As crianças estão sendo colocadas cada vez mais cedo e num período maior de tempo em instituições de educação infantil, portanto é importante que o ambiente escolar também seja avaliado, de forma que esse possa oferecer as melhores condições possíveis para o desenvolvimento infantil. Estes devem ser ambientes ricos em recursos em estimulação ao desenvolvimento de linguagem, principalmente na fase pré-escolar, fase na qual a criança começa a desenvolver conhecimentos e capacidade importantes para o bom desempenho não apenas escolar, mas também social e emocional ${ }^{8}$.

$\mathrm{O}$ atraso de linguagem causa prejuízos escolares significantes na vida das crianças. A detecção precoce desses atrasos, bem como o conhecimento dos seus fatores de risco e proteção, possibilita ações de promoção de saúde no campo da atenção primária em saúde com a melhor capacitação dos profissionais da área e organização de programas de intervenção na infância ${ }^{9}$.

Dada a relevância do tema, se faz primordial, inicialmente, a análise do conhecimento já produzido acerca dessa temática. Procurando oferecer subsídios que permitam reflexões e que tragam contribuições para a intervenção fonoaudiológica. Deste modo, o presente estudo tem o objetivo de descrever e analisar as produções científicas relevantes para o entendimento da influência do ambiente familiar e escolar na aquisição e desen- volvimento da linguagem em crianças por meio de revisão da literatura.

\section{MÉTODO}

Trata-se de uma revisão da literatura. Para construção do estudo as seguintes etapas foram realizadas: elaboração da pergunta norteadora, busca na literatura, coleta de dados, análise crítica dos estudos incluídos, discussão dos resultados e apresentação da revisão integrativa

A pergunta norteadora do presente estudo consistiu em: Qual a influência do ambiente familiar e da creche no desenvolvimento da linguagem infantil?

Foi realizado levantamento bibliográfico nas bases de dados do Portal Capes, Lilacs, a base em Ciências da Saúde em Geral da Bireme, Scielo e Google Acadêmico, sobre o assunto de interesse publicado no período de 2005 a 2010.

Os descritores utilizados nas pesquisas foram: ambiente, família, linguagem, fonoaudiologia, creches, desenvolvimento infantil e comunicação. Para a busca em inglês foram utilizados os seguintes descritores: language, speech, language development, speech language and hearing sciences, enviroment, day care center. Para realização da busca em espanhol foram utilizados os seguintes descritores: desarrollo infantil, desarollo del lenguaje, medio ambiente e comunicación.

Os critérios de inclusão dos artigos da presente revisão integrativa foram: artigos publicados completos em periódicos nacionais e internacionais; artigos que abordassem a temática do estudo, dentro da área de interesse da fonoaudiologia e artigos publicados nos últimos cinco anos. A busca às bases de dados resultou em 24 publicações.

A análise dos dados extraídos foi realizada de forma descritiva, em duas etapas. Na primeira, foram identificados os dados de localização do artigo, ano e periódico de publicação, autoria, objetivo, metodologia, resultados principais. $\mathrm{Na}$ segunda etapa ocorreu a análise crítica dos artigos e a discussão quanto ao "estado da arte" das produções na área, análise dos principais achados e avanços evidenciados pelos estudos, quais lacunas teóricas e "práticas" a serem preenchidas e perspectivas a serem consideradas em futuros estudos.

\section{REVISÃO DE LITERATURA}

A presente revisão de literatura é composta por 24 estudos, sendo 20 nacionais e 4 internacionais. Os estudos foram separados por eixos temáticos e serão apresentados a seguir. 
Nas Figuras de 1 a 3 estão apresentados a metodologia e os principais achados referentes à temática da influência do ambiente familiar e da creche no desenvolvimento fonológico e lexical infantil, segundo a distribuição pelos subtemas fonologia/ambiente, vocabulário/ambiente e ambiente familiar/creche/linguagem.

$\mathrm{Na}$ Figura 4 foram distribuídos os temas que foram mais estudados nos últimos 5 anos.

A Figura 5 apresenta um gráfico quantitativo dos estudos que abordaram os seguintes assuntos: escolaridade dos pais, nível socioeconômico, histórico do distúrbio na família, ambiente escolar, relação entre fonologia e vocabulário e categorização das alterações.

A Figura 6 apresenta os principais fatores indicadores de risco que aparecem nos artigos selecionados para a revisão bibliográfica, bem como as principais conclusões a que esses estudos chegaram.

O objetivo deste trabalho foi reunir informações relevantes para o entendimento da influencia do ambiente familiar e da creche no desenvolvimento da linguagem infantil.

De acordo com os dados da Tabela 1, verificouse que dos 8 artigos que estudaram a influência do ambiente no desenvolvimento fonológico infantil, 3 correlacionaram a presença do transtorno fonológico em um dos familiares com a alteração fonológica infantil ${ }^{10-12}$ e desses apenas um artigo não encontrou relação direta entre o transtorno fonológico em um dos familiares e a alteração fonológica infantil ${ }^{12}$. Apenas um artigo ${ }^{13}$ correlacionou a alteração fonológica nas crianças com nível de escolaridade dos pais. Os demais artigos ${ }^{14-17}$ verificaram variáveis como sexo, idade e nível socioeconômico da família. Por tanto, ressalta-se a necessidade mais estudos que verifiquem a influência do ambiente familiar com o desenvolvimento fonológico das crianças, além disso, é necessário que os autores utilizem mais de uma variável nos seus estudos. É importante destacar ainda o fato de não terem sido encontrados artigos que retratem a influência do ambiente da creche no desenvolvimento fonológico da criança, tornando-se evidente a necessidade de mais estudos na área.

Foram encontrados apenas 4 artigos ${ }^{18-21}$ que correlacionaram o ambiente com o desenvolvimento lexical das crianças (Figura 2). Nenhum dos artigos estudou o ambiente da creche como fator que influência o desenvolvimento lexical infantil. Nos artigos encontrados, as variáveis estudadas foram: renda familiar ${ }^{20}$, cujo estudo revelou que quanto maior a renda maior é a extensão frasal da criança; escolaridade dos pais ${ }^{19}$, e quanto menor a escolaridade materna e paterna maiores os riscos para o desenvolvimento infantil; estímulos presentes no ambiente familiar ${ }^{21}$, em que se observou o efeito de um ambiente estimulador, diretamente proporcional ao maior vocabulário expressivo na criança e por fim a idade da criança ${ }^{18}$, no qual se constatou que o número de nomeações aumenta à medida que a faixa etária avança.

Os temas de investigação variaram ao longo dos anos, no entanto, verificou-se uma escassez de publicações que abordem de forma mais profunda a relação entre ambiente e o desenvolvimento lexical e fonológico das crianças.

A Tabela 3 é composta por 8 artigos que tratam do desenvolvimento da linguagem infantil de crianças no ambiente familiar e escolar. Dos 6 artigos que estudaram o desenvolvimento da linguagem em escolares ${ }^{8,22-26}$ apenas 2 estudos 8,25 avaliaram a qualidade do estímulo ambiente escolar, levando em consideração fatores como escolaridade dos professores, tamanho do grupo de crianças e qualidade do ambiente da sala de aula e ambos os estudos encontraram relação direta entre o desenvolvimento da linguagem infantil e a qualidade do ambiente escolar. Pesquisas nesta área são importantes indicadores para a necessidade de melhorias no ambiente escolar, com conseqüente melhora para o desenvolvimento infantil.

Observa-se uma linha do tempo com os assuntos mais abordados pelos estudos nos últimos 5 anos. Os assuntos variaram ao longo dos anos, no entanto, verificou-se uma escassez de artigos que abordem de forma mais profunda a relação entre ambiente e o desenvolvimento lexical e fonológico das crianças. Ressalta-se ainda a necessidade de pesquisas que utilizem instrumentos padronizados que avaliem o ambiente familiar e escolar (Figura 4).

A análise da frequência de temas mais abordados pelos artigos indicou que muitos autores preocupam-se com a categorização das alterações ${ }^{14-18}$ e menos com as causas das mesmas. Averiguou-se que as variáveis relacionadas ao ambiente escolar e familiar ainda são pouco exploradas, indicando a necessidade de estudos que aprofundem seus conhecimentos nessas variáveis. Além disso, percebe-se que a grande maioria dos artigos utiliza duas a três variáveis no controle de sua pesquisa; por exemplo, idade, sexo e escolaridade materna, ou ainda escolaridade dos pais e nível socioeconômico. É importante que os estudos busquem analisar o maior número possível de variáveis que incluam o ambiente em que a criança se encontra inserida. Somente dessa forma, será possível apresentar resultados significantes a respeito da influência do ambiente no desenvolvimento da linguagem infantil (Figura 5). Dentre 


\begin{tabular}{|c|c|c|c|}
\hline Autor/ ano & Objetivo & Método & Principais conclusões \\
\hline $\begin{array}{c}\text { Papp, } \\
\text { Wertzner } 2006\end{array}$ & $\begin{array}{l}\text { Verificar os processos fonológicos } \\
\text { realizados por crianças com transtorno } \\
\text { fonológico entre } 3: 6 \text { - 10:2 anos de idade } \\
\text { com e sem história de transtorno de fala } \\
\text { e linguagem em seus familiares e } \\
\text { verificar associação entre os processos } \\
\text { fonológicos usados pelas crianças com } \\
\text { transtorno fonológico e seus familiares. }\end{array}$ & $\begin{array}{l}\text { Delineamento: estudo transversal } \\
\text { Casuística: } 25 \text { crianças com Transtorno } \\
\text { fonológico e seus familiares, somando } \\
104 \text { sujeitos. } \\
\text { Instrumento da coleta: roteiro de } \\
\text { anamnese, um questionário e as provas } \\
\text { de fonologia do Teste de Linguagem } \\
\text { Infantil ABFW. } \\
\text { Análise: multivariada }\end{array}$ & $\begin{array}{l}\text { O processo fonológico de simplificação } \\
\text { de líquidas foi o mais utilizado em todos } \\
\text { os subgrupos das crianças. Os } \\
\text { subgrupos com familiares com transtorno } \\
\text { fonológico foram os que mais usaram os } \\
\text { processos de ensurdecimento de } \\
\text { plosivas. Observou-se que existem } \\
\text { fatores que indicam que o histórico de } \\
\text { transtorno de fala e linguagem em } \\
\text { familiares está associado ao transtorno } \\
\text { fonológico. }\end{array}$ \\
\hline $\begin{array}{c}\text { Casarin et al. } \\
2006\end{array}$ & $\begin{array}{l}\text { Estimar a prevalência de desvio de fala } \\
\text { em uma amostra de pré-escolares de } \\
\text { escolas públicas, verificar a prevalência } \\
\text { do desvio quanto ao sexo, classificar os } \\
\text { desvios quanto ao tipo e à severidade, } \\
\text { verificar se em crianças com desvios } \\
\text { fonológicos há presença de atraso na } \\
\text { aquisição da linguagem, caracterizar o } \\
\text { inventário fonético e o sistema fonológico } \\
\text { e verificar quais os fonemas mais } \\
\text { alterados. }\end{array}$ & $\begin{array}{l}\text { Delineamento: transversal } \\
\text { Casuística:91 sujeitos, com idades entre } \\
5: 7 \text { e } 7: 5 \text { anos } \\
\text { Instrumento da coleta: avaliações } \\
\text { fonoaudiológicas e fonológica Análise: } \\
\text { multivariada }\end{array}$ & $\begin{array}{l}\text { Dos } 91 \text { sujeitos, } 70,3 \% \text { apresentaram } \\
\text { fala com desvio, e os outros } 29,7 \% \\
\text { apresentaram aquisição de fala } \\
\text { normalizada. Não foi constatada } \\
\text { associação entre atraso no processo de } \\
\text { aquisição da linguagem e tipo de desvio. } \\
\text { Verificou-se associação estatisticamente } \\
\text { significante entre o sexo masculino e o } \\
\text { grupo com desvio de fala. }\end{array}$ \\
\hline $\begin{array}{l}\text { Goulart, } \\
\text { Chiari } \\
2007\end{array}$ & $\begin{array}{l}\text { Verificar a ocorrência de alterações de } \\
\text { fala de origem fonética, fonológica ou } \\
\text { fonético-fonológica em escolares e } \\
\text { fatores a elas } \\
\text { associados. }\end{array}$ & $\begin{array}{l}\text { Delineamento: estudo transversal } \\
\text { Casuística: } 1.810 \text { crianças com idades } \\
\text { entre cinco e } 11 \text { anos. } \\
\text { Instrumento da coleta: Teste de } \\
\text { Rastreamento de Distúrbios Articulatórios } \\
\text { de Fala (TERDAF), } \\
\text { Análise: multivariada }\end{array}$ & $\begin{array}{l}\text { A prevalência de desordens de fala nas } \\
\text { crianças foi de } 24,6 \% \text { e maior em } \\
\text { crianças com cinco a seis anos. A } \\
\text { prevalência de alteração de fala por volta } \\
\text { dos cinco anos de idade foi de } 57 \% \text {. A } \\
\text { proporção de alteração de fala foi } \\
\text { semelhante entre os sexos. As } \\
\text { alterações se associaram ao grau de } \\
\text { escolaridade das mães e dos pais, } \\
79,5 \% \text { e } 78,6 \% \text {, respectivamente, com } \\
\text { menos de um ano de estudo. A } \\
\text { escolaridade dos pais foi importante fator } \\
\text { associado às alterações. }\end{array}$ \\
\hline $\begin{array}{l}\text { Vitor, Martins } \\
2007\end{array}$ & $\begin{array}{l}\text { Descrever o desenvolvimento fonológico } \\
\text { de crianças em idade pré-escolar } \\
\text { falantes da variante mineira do } \\
\text { Português Brasileiro. }\end{array}$ & $\begin{array}{l}\text { Delineamento: estudo transversal } \\
\text { Casuística: } 95 \text { crianças } \\
\text { Instrumento de coleta: } \\
\text { Análise: Quantitativa }\end{array}$ & $\begin{array}{l}35 \text { crianças não realizaram qualquer } \\
\text { processo fonológico. Os processos } \\
\text { fonológicos mais freqüentes foram os de } \\
\text { substituição de consoantes líquidas e } \\
\text { redução de encontro consonantal. As } \\
\text { variações no desenvolvimento fonológico } \\
\text { correlacionaram-se com variações na } \\
\text { idade das crianças. }\end{array}$ \\
\hline $\begin{array}{l}\text { Cavalheiro, - } \\
\text { Soares } \\
2008\end{array}$ & $\begin{array}{l}\text { Verificar a prevalência do desvio } \\
\text { fonológico em crianças de } 4 \text { a } 6 \text { anos de } \\
\text { idade }\end{array}$ & $\begin{array}{l}\text { Delineamento: estudo transversal } \\
\text { Casuística: } 2880 \text { crianças, na faixa etária } \\
\text { de 4:0anos a 6:11 anos } \\
\text { Instrumento da coleta: } \\
\text { Análise: multivariada }\end{array}$ & $\begin{array}{l}264 \text { crianças apresentavam desvio } \\
\text { fonológico revelando uma prevalência de } \\
9,17 \% \text { de crianças com desvio } \\
\text { fonológico. Foi possível verificar que de } \\
\text { todas as crianças com diagnóstico de } \\
\text { desvio fonológico } 47 \% \text { apresentavam um } \\
\text { membro na família com diagnóstico } \\
\text { semelhante e na mesma faixa etária } \\
\text { estudada. }\end{array}$ \\
\hline $\begin{array}{c}\text { Ferrante et al } \\
2008\end{array}$ & $\begin{array}{l}\text { Investigar a aquisição fonológica em uma } \\
\text { população de crianças com } \\
\text { desenvolvimento } \\
\text { normal. }\end{array}$ & $\begin{array}{l}\text { Delineamento: estudo transversal } \\
\text { Casuística: } 240 \text { crianças, com idades } \\
\text { entre três e oito anos. } \\
\text { Instrumento da coleta: } \\
\text { Análise: mullivariada }\end{array}$ & $\begin{array}{l}\text { A aquisição do fonema /r/ ocorre } \\
\text { inicialmente na posição de onset simples } \\
\text { (quatro anos) e posteriormente na } \\
\text { posição de onset complexo (cinco anos), } \\
\text { a aquisição do fonema /// em onset } \\
\text { simples ocorre aos três anos e em onset } \\
\text { complexo aos quatro anos e o fonema } \\
\text { /R/ em onset simples é adquirido na faixa } \\
\text { etária de três anos e na posição de coda } \\
\text { aos quatro anos. }\end{array}$ \\
\hline $\begin{array}{l}\text { Ferrante et al } \\
2009\end{array}$ & $\begin{array}{l}\text { Verificar o uso dos processos fonológicos } \\
\text { em uma população de crianças com } \\
\text { desenvolvimento fonológico normal }\end{array}$ & $\begin{array}{l}\text { Delineamento: estudo transversal } \\
\text { Casuística: } 240 \text { crianças, com idades } \\
\text { entre três e oito anos. } \\
\text { Instrumento da coleta: } \\
\text { Análise: multivariada }\end{array}$ & $\begin{array}{l}\text { Aos três, quatro e cinco anos os } \\
\text { processos de redução de encontro } \\
\text { consonantal, lateralização e apagamento } \\
\text { de consoante final foram os mais } \\
\text { utilizados. Em relação ao número de } \\
\text { processos fonológicos o número diminuiu } \\
\text { gradativamente de acordo com o } \\
\text { aumento da faixa etária, assim como a } \\
\text { média. }\end{array}$ \\
\hline $\begin{array}{c}\text { Pagliarin et al } \\
2010\end{array}$ & $\begin{array}{l}\text { O estudo teve como objetivo analisar a } \\
\text { relação entre os fatores familiares e as } \\
\text { diferentes gravidades do desvio } \\
\text { fonológico. }\end{array}$ & $\begin{array}{l}\text { Delineamento: estudo transversal } \\
\text { Casuística: } 152 \text { crianças } \\
\text { Instrumento da coleta: } \\
\text { Análise: multivariada }\end{array}$ & $\begin{array}{l}\text { Os aspectos familiares estudados } \\
\text { parecem não ter relação direta com a } \\
\text { gravidade do desvio fonológico, com } \\
\text { exceção de distúrbios psicológicos nas } \\
\text { criaças com desvio fonológico leve. }\end{array}$ \\
\hline
\end{tabular}

Figura 1 - Sinopse dos estudos que correlacionam o desenvolvimento fonológico infantil com o ambiente em que a criança encontra-se inserida 


\begin{tabular}{|c|c|c|c|}
\hline Autor/ ano & Objetivo & Método & Principais conclusões \\
\hline $\begin{array}{c}\text { Hage, Pereira } \\
2006\end{array}$ & $\begin{array}{l}\text { Obter o perfil de crianças com } \\
\text { desenvolvimento típico de linguagem em } \\
\text { prova de vocabulário expressivo, e } \\
\text { verificar os tipos de desvios semânticos } \\
\text { mais utilizados por elas. }\end{array}$ & $\begin{array}{l}\text { Delineamento: descritivo correlacional } \\
\text { Casuística: } 400 \text { crianças entre três anos } \\
\text { e seis anos. } \\
\text { Instrumento da coleta: protocolo de } \\
\text { avaliação lexical com } 100 \text { itens. } \\
\text { Análise: multivariada }\end{array}$ & $\begin{array}{l}\text { As crianças de cinco e seis anos } \\
\text { obtiveram desempenho semelhante e } \\
\text { superior às crianças de três e quatro } \\
\text { anos quanto ao número de itens } \\
\text { nomeados, e o número de itens não } \\
\text { nomeados aumentou conforme diminuiu } \\
\text { a idade. }\end{array}$ \\
\hline $\begin{array}{c}\text { Mengela, } \\
\text { Linhares } 2007\end{array}$ & $\begin{array}{l}\text { Detectar riscos para problemas do } \\
\text { desenvolvimento da criança nos quatro } \\
\text { primeiros anos, identificar recursos } \\
\text { protetores no ambiente familiar e verificar } \\
\text { as melhores variáveis preditoras do } \\
\text { desenvolvimento em risco. }\end{array}$ & $\begin{array}{l}\text { Delineamento: descritivo correlacional. } \\
\text { Casuística: } 120 \text { crianças de } 6 \text { a } 44 \\
\text { meses. } \\
\text { Instrumento da coleta: Teste de Denver-II } \\
\text {, Roteiro de Entrevista para Risco } \\
\text { Biopsicossocial, Índice de Risco } \\
\text { Psicossocial, Escala de Eventos } \\
\text { Vitais(15) e Questionário ABIPEME } \\
\text { (Associação Brasileira de Institutos de } \\
\text { Pesquisa de Mercado) e o Inventário } \\
\text { HOME } \\
\text { Análise: multivariada }\end{array}$ & $\begin{array}{l}\text { Quanto menor a escolaridade do pai, } \\
\text { maior a chance de risco para problemas } \\
\text { de desenvolvimento. A história do estado } \\
\text { nutricional abaixo do normal aos seis } \\
\text { meses de idade e o risco psicossocial no } \\
\text { ambiente familiar aumentava a } \\
\text { probabilidade de problemas de } \\
\text { linguagem expressiva. }\end{array}$ \\
\hline $\begin{array}{l}\text { Frasson } \\
\text { et al. } \\
2009\end{array}$ & $\begin{array}{l}\text { Comparar a linguagem expressiva de } \\
\text { crianças nascidas pré-termo com o de } \\
\text { crianças nascidas a termo aos dois anos } \\
\text { de vida }\end{array}$ & $\begin{array}{l}\text { Delineamento: retrospectivo } \\
\text { Casuística: } 118 \text { protocolos de avaliação } \\
\text { fonoaudiológica. } \\
\text { Instrumento da coleta: Lista de Avaliação } \\
\text { do Vocabulário Expressivo. } \\
\text { Análise: multivariada }\end{array}$ & $\begin{array}{l}\text { Crianças pré-termo e de baixo peso } \\
\text { apresentam maior ocorrência de atraso } \\
\text { na linguagem expressiva. A renda } \\
\text { familiar demonstrou associação positiva } \\
\text { à extensão frasal, assim como as } \\
\text { condições de nascimento, idade } \\
\text { gestacional e peso ao nascer, também } \\
\text { associados ao número de palavras } \\
\text { produzidas. }\end{array}$ \\
\hline $\begin{array}{l}\text { Hart et al } \\
2010\end{array}$ & $\begin{array}{l}\text { Avaliar se o ambiente familiar influencia } \\
\text { no vocabulário expressivo. Avaliar se o } \\
\text { ambiente familiar pode representar uma } \\
\text { parte da convariância longitudinal ,ou de } \\
\text { estabilidade ao longo do tempo, no } \\
\text { vocabulário expressivo de gêmeos em } \\
\text { idade escolar. }\end{array}$ & $\begin{array}{l}\text { Delineamento: longitudinal } \\
\text { Casuística: } 314 \text { pares de gêmeos, sendo } \\
128 \text { pares de gêmeos monozigóticos e } \\
175 \text { pares de gêmeos dizigóticos. } \\
\text { Instrumento da coleta: Boston Naming } \\
\text { Test (BNT), e relatos das mães } \\
\text { Análise: descritiva }\end{array}$ & $\begin{array}{l}\text { Um ambiente familiar estimulador está } \\
\text { associado com maior vocabulário } \\
\text { expressivo de crianças. Os resultados } \\
\text { sugerem que o ambiente de casa, e o } \\
\text { investimento parental na aprendizagem, } \\
\text { é um aspecto significante na capacidade } \\
\text { expressiva da criança vocabulário }\end{array}$ \\
\hline
\end{tabular}

Figura 2- Sinopse dos estudos que correlacionam o desenvolvimento lexical infantil com o ambiente em que a criança encontra-se inserida

os estudos relacionados para este estudo, foram encontrados fatores de risco que estão listados pela literatura e que podem influenciar o desenvolvimento da linguagem, esses fatores serão discutidos a seguir (Figura 6).

A analise dos resultados revelou que a variável ambiental mais estudada foi a escolaridade dos pais $9,13,19,24,26-28,30$. Parte dos estudos mostrou que há influência da escolaridade materna ${ }^{13,24,26,28} \mathrm{e}$ apenas dois estudos relacionaram a influência da escolaridade paterna no desenvolvimento infantil ${ }^{13,19}$. Os estudos que relataram influência da escolaridade materna e paterna no desenvolvimento infantil mostraram que quanto maior o tempo de estudo dos pais menor é a chance de as crianças apresentarem alterações, o que indica a importância do nível de escolaridade dos pais na promoção do desenvolvimento infantil.

A segunda variável ambiental e fator de risco mais estudado nos últimos 5 anos, foi a influência do nível sócio econômico no desenvolvimento infantil ${ }^{20,22,24}$. Um estudo ${ }^{20}$ indicou que quanto maior a renda familiar, melhor a estruturação frasal além de ser um dos fatores que influenciam na quantidade e qualidade de estímulos fornecidos.

O histórico de distúrbio fonológico na família ${ }^{10-12}$ foi a terceira variável mais estudada sendo que alguns estudos revelaram que crianças que apresentam desvio fonológico possuem membros na família com alterações similares, o que poderia influenciar no desenvolvimento do distúrbio ${ }^{10,11}$. Tais estudos não corroboram parte da literatura ${ }^{12}$, que revela não haver associação entre o histórico familiar de alteração fonológica e o desenvolvimento da alteração na criança. Assim, verificouse controvérsias quanto à influência do histórico familiar no distúrbio fonológico na criança, sendo necessária a realização de investigações adicionais para verificar tal fator. Apesar de vários estudos terem sido realizados no ambiente escolar ${ }^{8,14,23-25}$, apenas dois consideraram a avaliação do ambiente da escola ${ }^{8,25}$. Deste modo verifica-se que há pouca pesquisa orientada para esta variável. Deve-se considerar o ambiente escolar como um importante indicador devido ao tempo em as crianças permenecem nesse ambiente. 


\begin{tabular}{|c|c|c|c|}
\hline Autor/ ano & Objetivo & Método & Principais conclusões \\
\hline $\begin{array}{l}\text { Andrade } \\
\text { et al. } \\
2005\end{array}$ & $\begin{array}{l}\text { Analisar a associação entre a qualidade } \\
\text { do estímulo doméstico e o desempenho } \\
\text { cognitivo infantil, identificando o impacto } \\
\text { da escolaridade materna sobre a } \\
\text { qualidade dessa estimulação. }\end{array}$ & $\begin{array}{l}\text { Delineamento: transversal } \\
\text { Casuística: } 350 \text { crianças entre } 17 \text { e } 42 \\
\text { meses. } \\
\text { Instrumento da coleta: Inventário Home } \\
\text { Observation for Measurement of the } \\
\text { Environment Scale (HOME) e a escala } \\
\text { Bayley de desenvolvimento infantil. } \\
\text { Análise: univariadas e múltiplas. }\end{array}$ & $\begin{array}{l}\text { Associação positiva e estatisticamente } \\
\text { significante entre a qualidade da } \\
\text { estimulação no ambiente doméstico e o } \\
\text { desempenho cognitivo infantil. }\end{array}$ \\
\hline $\begin{array}{l}\text { Rezende } \\
\text { et al. } \\
2005\end{array}$ & $\begin{array}{l}\text { Avaliar, pelo segundo ano consecutivo, } \\
\text { habilidades das áreas de linguagem e } \\
\text { pessoal-social de uma coorte de crianças } \\
\text { que frequentam } 3 \text { creches da cidade de } \\
\text { São Paulo. }\end{array}$ & $\begin{array}{l}\text { Delineamento: } \\
\text { Casuística: } 30 \text { crianças de } 0 \text { a } 4 \text { anos, de } \\
\text { nível sócio-econômico homogêneo } \\
\text { Instrumento da coleta: Teste de Triagem } \\
\text { de Desenvolvimento de Denver II. } \\
\text { Análise: múltiplas }\end{array}$ & $\begin{array}{l}\text { Na área pessoal-social a melhora foi } \\
\text { significante da } 1^{\underline{\underline{a}}} \text { para a } 2^{\underline{a}} \text { avaliaçãa, o } \\
\text { que não ocorreu na área de linguagem, } \\
\text { ao longo das } 3 \text { avaliaçães. No entanto, a } \\
\text { partir dos } 3 \text { anos de idade as crianças } \\
\text { passaram a obter resultados piores. }\end{array}$ \\
\hline $\begin{array}{l}\text { Rezende } \\
\text { et al. } \\
2005\end{array}$ & $\begin{array}{l}\text { Realizar a triagem do desenvolvimento } \\
\text { de crianças de dois a três anos de idade, } \\
\text { que freqüentam IEls públicas, e } \\
\text { estabelecer hipótese de relação entre } \\
\text { tais resultados e algumas condições } \\
\text { estruturais destas instituições e as } \\
\text { condições socio-econômicas das } \\
\text { famílias. }\end{array}$ & $\begin{array}{l}\text { Delineamento:transversal } \\
\text { Casuística: } 66 \text { criança de } 2 \text { a } 3 \text { anos. } \\
\text { Instrumento da coleta:Teste de Triagem } \\
\text { de Desenvolvimento de Denver II. } \\
\text { Análise:multivariada }\end{array}$ & $\begin{array}{l}\text { Nas áreas de linguagem e pessoal- } \\
\text { social, as crianças obtiveram os piores. } \\
\text { Levantou- se como hipóteses: os } \\
\text { resultados de linguagem e pessoal social } \\
\text { foram prejudicados pelas condições das } \\
\text { IEIS (escolaridade das educadoras e } \\
\text { tamanho dos grupos de crianças) e } \\
\text { talvez pela situação familiar. }\end{array}$ \\
\hline $\begin{array}{l}\text { Cachapuz, } \\
\text { Halpern } \\
2006\end{array}$ & $\begin{array}{l}\text { Determinar a prevalência de suspeita de } \\
\text { atraso de linguagem } \\
\text { e possíveis associações entre fatores } \\
\text { ambientais e biológicos em uma amostra } \\
\text { de crianças de até seis anos. }\end{array}$ & $\begin{array}{l}\text { Delineamento:analítico observacional } \\
\text { transversal. } \\
\text { Casuística: quarenta clusters } \\
\text { Instrumento da coleta: questionário para } \\
\text { as mães das crianças contendo questões } \\
\text { que contemplavam o histórico } \\
\text { gestacional, neonatal e o } \\
\text { desenvolvimento ao longo da infância e } \\
\text { Teste de Denver. } \\
\text { Análise: multivariada }\end{array}$ & $\begin{array}{l}\text { Os resultados mostram uma prevalência } \\
\text { de suspeita de atraso de linguagem de } \\
26 \% \text { das } 204 \text { crianças avaliadas. Os } \\
\text { fatores ambientais e biológicos que se } \\
\text { associaram ao desfecho no modelo final } \\
\text { da regressão logística foram: renda } \\
\text { familiar, escolaridade materna, intervalo } \\
\text { interpartal, interesse da criança e } \\
\text { estímulo à linguagem. }\end{array}$ \\
\hline $\begin{array}{l}\text { Lima, Bhering } \\
2006\end{array}$ & $\begin{array}{l}\text { Avaliar a qualidade do ambiente das } \\
\text { salas de aulas e das instituições para } \\
\text { crianças entre } 4 \text { e } 36 \text { meses de idade. }\end{array}$ & $\begin{array}{l}\text { Delineamento:descritivo } \\
\text { Casuística: doze salas de creches com } \\
\text { crianças na faixa etária entre } 3 \text { a } 38 \\
\text { meses. } \\
\text { Instrumento: escala Iters-R. } \\
\text { Análise: multivariada }\end{array}$ & $\begin{array}{l}\text { Os itens Atividades e Cuidado Pessoal } \\
\text { tiveram os escores médios mais baixos } \\
\text { em todas as instituições; Interação e Pais } \\
\text { e equipe, os escores médios mais altos. } \\
\text { Quanto às turmas, as de três anos foram } \\
\text { as que apresentaram os piores } \\
\text { resultados. }\end{array}$ \\
\hline $\begin{array}{l}\text { Biscegli et al. } \\
2007\end{array}$ & $\begin{array}{l}\text { Avaliar o estado nutricional e o } \\
\text { desenvolvimento neuropsicomotor em } \\
\text { crianças freqüentadoras de uma creche. }\end{array}$ & $\begin{array}{l}\text { Delineamento: transversal } \\
\text { Casuística: } 113 \text { crianças com seis a } 70 \\
\text { meses de idade. } \\
\text { Instrumento da coleta: avaliação } \\
\text { nutricional feita por antropometria, Teste } \\
\text { de Denver II e questionários respondido } \\
\text { pelos pais em } 70 \% \text { dos casos. } \\
\text { Análise:multivariada }\end{array}$ & $\begin{array}{l}\text { O Teste de Denver II detectou } 37 \% \text { de } \\
\text { suspeitos de atraso no desenvolvimento, } \\
\text { sendo a linguagem a área mais } \\
\text { acometida. A faixa etária mais } \\
\text { comprometida foi a de } 25 \text { a } 60 \text { meses. } \\
\text { questionário mostrou que } 87 \% \text { das } \\
\text { crianças receberam aleitamento materno, } \\
96 \% \text { das mães trabalhavam fora de casa, } \\
54 \% \text { delas possuíam ensino médio } \\
\text { completo e } 73 \% \text { das famílias tinham } \\
\text { renda máxima de dois salários-mínimos. }\end{array}$ \\
\hline $\begin{array}{l}\text { Ferreira e } \\
\text { Maturano } \\
2008\end{array}$ & $\begin{array}{l}\text { Este estudo focaliza precursores de } \\
\text { competência na transição da } 1^{\underline{a}} \text { série. }\end{array}$ & $\begin{array}{l}\text { Delineamento: estudo prospectivo } \\
\text { Casuística: } 70 \text { crianças da } 1^{\underline{a}} \text { série. } \\
\text { Instrumento da coleta: } \\
\text { Análise: multivariada }\end{array}$ & $\begin{array}{l}\text { Variáveis da criança e da família } \\
\text { predisseram ajustamento e desempenho. } \\
\text { Consciência fonológica e nível intelectual } \\
\text { foram os melhores preditores de } \\
\text { desempenho e ajustamento, } \\
\text { respectivamente. Crianças com } \\
\text { experiência prévia na educação infantil } \\
\text { mostraram menor estresse que crianças } \\
\text { sem experiência. }\end{array}$ \\
\hline $\begin{array}{l}\text { Schonhaut } \\
\text { et al. } \\
2008\end{array}$ & $\begin{array}{l}\text { Estabelecer a correlação entre } \\
\text { linguagem e inteligência, identificar } \\
\text { possíveis fatores associados em pré- } \\
\text { escolares de baixo nível sócio econômico } \\
\text {. }\end{array}$ & $\begin{array}{l}\text { Delineamento: estudo transversal } \\
\text { analítico } \\
\text { Casuística: } 61 \text { crianças de } 3 \text { a } 5 \text { anos. } \\
\text { Instrumento da coleta: Test de Procesos } \\
\text { de Simplificación Fonológica, Test } \\
\text { Exploratorio de Gramática Española de } \\
\text { A. Toronto avaliação audiológica, teste } \\
\text { WPSSI e evolução pediátrica e } \\
\text { neurológica completa. } \\
\text { Análise: descritiva e analítica de acordo } \\
\text { com a natureza das variáveis }\end{array}$ & $\begin{array}{l}\text { Em } 22 \text { crianças identificou-se } \\
\text { dificuldades de linguagem (DL). O } \\
\text { rendimento cognitivo seguiu uma } \\
\text { distribuição normal. Ocorreu correlação } \\
\text { significante entre inteligencia e } \\
\text { linguagem. As crianças com DL } \\
\text { apresentaram menor rendimento } \\
\text { cognitivo, tanto verbal como de } \\
\text { execução. O antecedente familiar de DL, } \\
\text { os trastornos de aprendizagem e historia } \\
\text { de déficit de desenvolvimento } \\
\text { psicomotor se associaram a menor } \\
\text { rendimento de linguagem. Os filhos de } \\
\text { mães com ensino superior apresentaram } \\
\text { melhor rendimento no potencial } \\
\text { cognitivo. }\end{array}$ \\
\hline
\end{tabular}

Figura 3 - Sinopse dos estudos que abordam a influencia do ambiente familiar e da creche e o papel de cada um no desenvolvimento da linguagem infantil 


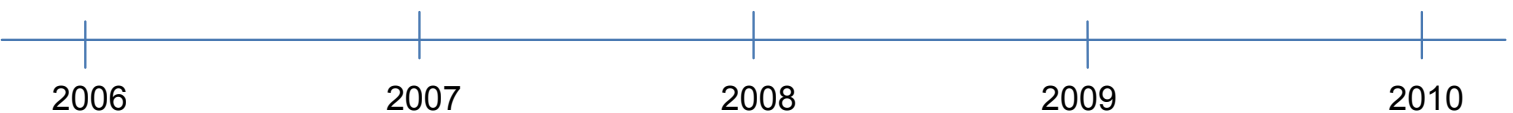

\author{
Os ambientes em \\ que as crianças \\ encontram-se \\ inseridas \\ influenciam no \\ desenvolvimento \\ da linguagem
}
A escolaridade dos pais interfere no desenvolvimento da linguagem.

A maioria das crianças que apresentam alteração fonológica possuem ao menos um familiar com alteração semelhante a sua.

\section{A alteração \\ fonológica \\ influencia no \\ desenvolvimento \\ do vocabulário \\ infantil.}

Fatores familiares influenciam o desenvolvimento fonológico e o desempenho escolar das crianças.

\section{Figura 4 - Cronologia dos estudos de acordo com os assuntos mais abordados em cada ano}

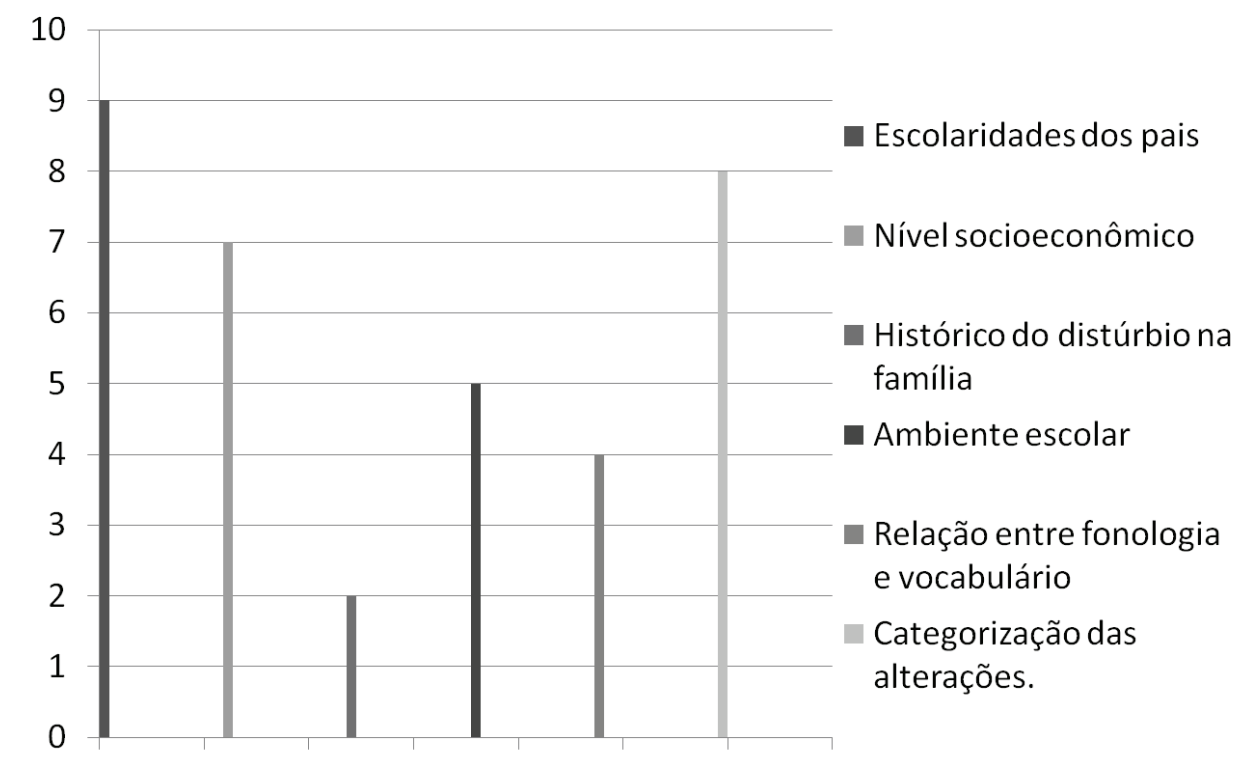

Figura 5 - Gráfico quantitativo dos assuntos pesquisados nos artigos

A escolaridade das educadoras e ao grande número de alunos em sala de aula também foram considerados fatores de risco para o desenvolvimento da linguagem ${ }^{8}$. Um estudo mostrou que quanto menor o grau de escolaridade das educadoras e maior o número de alunos por sala de aula pior a qualidade dos estímulos oferecidos para o desenvolvimento da linguagem. Visto a importância do ambiente escolar no qual a criança está inserida é relevante o estudo que correlacione a capacitação dos profissionais e a qualidade do estimulo que a criança recebe.

Dentre os fatores de risco abordados, foi mostrado que crianças de mães que trabalham fora e que convivem com companheiro no ambiente familiar apresentam melhor estimulação e desenvolvimento de linguagem ${ }^{28}$. Outro fator abordado foi a influência da quantidade de irmãos. O estudo apontou que crianças mais velhas que convivem com número reduzido de irmãos menores aproveitam melhor a qualidade da estimulação do ambiente familiar ${ }^{28}$. Visto que poucos estudos abordam os temas acima fazem-se necessárias novas pesquisas que elucidem a influência de tais fatores no desenvolvimento da linguagem.

Deve-se ressaltar ainda que, apesar de terem sido encontrados alguns artigos que correlacionem fonologia e vocabulário ${ }^{29-33}$, nenhum dos estudos correlaciona esses dois fatores juntos com a variável ambiente. Sendo assim ratifica-se a necessidade do desenvolvimento de estudos a respeito da temática supracitada.

Dentre os indicadores de risco encontrados apenas um estudo abordou a prematuridade e baixo 


\begin{tabular}{|l|l|}
\hline Principais Indicadores de risco & Conclusões \\
\hline Escolaridade dos pais & $\begin{array}{l}\text { Quanto maior o grau de escolaridade dos pais } \\
\text { melhor o estímulo e maior o grau de } \\
\text { desenvolvimento da linguagem das crianças. }\end{array}$ \\
\hline Nível socioeconômico familiar & $\begin{array}{l}\text { Está relacionado com o modelo de estruturação } \\
\text { frasal e influencia o desenvolvimento a medida } \\
\text { que é um dos fatores determinantes da } \\
\text { quantidade e qualidade do estímulo fornecido. }\end{array}$ \\
\hline Distúrbio fonológico em familiares & $\begin{array}{l}\text { É comum crianças que apresentam distúrbio } \\
\text { fonológico possuírem pelo menos um familiar com } \\
\text { alteração semelhante a sua. }\end{array}$ \\
\hline Crianças nascidas pré-termo e de baixo peso. & $\begin{array}{l}\text { Apresentam maior índice de atraso no } \\
\text { desenvolvimento da linguagem. }\end{array}$ \\
\hline Presença de irmãos & $\begin{array}{l}\text { As crianças mais velhas que convivem com } \\
\text { número reduzido de irmãos menores aproveitam } \\
\text { melhor a qualidade da estimulação do ambiente } \\
\text { familiar. }\end{array}$ \\
\hline $\begin{array}{l}\text { Mães que trabalham fora e convivem com } \\
\text { companheiros no ambiente familiar. }\end{array}$ & $\begin{array}{l}\text { As crianças que vivem nessas situações recebem } \\
\text { melhor estimulação e apresentam melhor } \\
\text { desenvolvimento da linguagem. }\end{array}$ \\
\hline $\begin{array}{l}\text { Escolaridade das educadoras e tamanho } \\
\text { da sala de aula. }\end{array}$ & $\begin{array}{l}\text { Quanto menor o grau de escolaridades das } \\
\text { educadores e maior o número de alunos por sala } \\
\text { de aula piores são a qualidade dos estímulos } \\
\text { oferecidos para o desenvolvimento da linguagem }\end{array}$ \\
\hline Sexo & $\begin{array}{l}\text { Os meninos apresentam mais alterações de } \\
\text { linguagem quando comparados às meninas. }\end{array}$ \\
\hline
\end{tabular}

Figura 6 - Principais fatores de riscos encontrados nos artigos que compõem a presente revisão de literatura

peso ao nascer como fatores que podem influenciar o desenvolvimento do léxico infantil 20 . O estudo revelou que crianças pré-termo apresentam vocabulário expressivo inferior ao de crianças a termo. A prevalência de alterações de desenvolvimento de linguagem entre os sexos foi abordada em um estudo ${ }^{17}$, que não encontrou diferença com significância estatística entre o desempenho de ambos os sexos e a quantidade de processos fonológicos encontrada. Os achados acima mostram a necessidade de novas produções que abordem a influência dos indicadores citados acima para que possíveis dúvidas sejam solucionadas.

Foram encontrados, ainda, estudos que correlacionam fonologia e vocabulário ${ }^{29-33}$. A maioria dos estudos mostrou que crianças que apresentam distúrbio fonológico apresentam resultados inferiores nas provas de vocabulário, quando comparado às crianças que não apresentam alteração fonológica ${ }^{31-33}$,tais resultados não corroboraram outro estudo que apontou que não há relação entre alteração fonológica e vocabulário ${ }^{30}$. Deste modo verifica-se a necessidade de que se realizem mais estudos que relacionem fonologia e vocabulário, devido a importância de ambos no desenvolvimento da linguagem.

Deve-se ressaltar ainda que, apesar de terem sido encontrados artigos que correlacionem fonologia e vocabulário, nenhum dos estudos correlaciona esses dois fatores juntos com a variável ambiente. Sendo assim ratifica-se a necessidade de que se desenvolvam estudos a respeito da temática supracitada.

\section{CONCLUSÃO}

Um adequado desenvolvimento da linguagem depende de fatores intrínsecos e extrínsecos. As influências do ambiente no qual a criança está inserida é de grande importância para o desenvolvimento lexical e fonológico. As produções científicas apresentadas apontam a relevância da estimulação no âmbito familiar e escolaridade dos pais, porém pôde-se perceber a carência de estudos que relacionassem o desenvolvimento infantil com o ambiente escolar, visto que este é de grande importância na 
aquisição e desenvolvimento da linguagem. Outro fator que chamou atenção foi a falta de estudos que correlacionem vocabulário e fonologia com os fatores ambientais escolares e familiares.

Além das questões citadas, observou-se nos estudos, a falta do uso de protocolos padronizados para a realização das avaliações, além do não uso de todas as variáveis ambientais que podem influenciar no desenvolvimento da criança.

A pesquisa bibliográfica mostra lacunas e indica novas perspectivas de trabalhos a serem realizados na Fonoaudiologia.

\begin{abstract}
Background: the term language is defined as organized system of symbols, with properties, that has a role in encoding, consolidation and structuring sensory data, allowing for experiments to be reported and their contents communicated. Language development depends not just on the innate biological conditions of each individual, but is also influenced by environmental factors in the environments where children are inserted, such as family and school. Purpose: to describe and analyze scientific studies relevant to understanding the influence of family and school environment in language acquisition and development in children through a literature review. Conclusion: the scientific studies point out to the importance of stimulation in the family and parents' education, but one can perceive a lack of studies in children's development within school environment. Another factor that drew attention was the lack of studies to correlate vocabulary and phonology with the school and familial environmental factors. From the literature review opens up new prospects for work to be performed in speech pathology so that such gaps can be filled up with new knowledge on child development.
\end{abstract}

KEYWORDS: Environment; Family; Language; Speech, Language and Hearing Sciences; Child Day Care Centers; Child Development

\section{REFERÊNCIAS}

1. Azcoaga JE, Bello JA, Citrinovitz J, Derman B, Frutos WM. 2a ed. Los retardos del lenguage en el niño. Buenos Aires: Paidós; 1997.

2. Wertzner HF. Distúrbio Fonológico. In: LIMONGI, SCO. Linguagem: desenvolvimento normal, alterações e distúrbios. São Paulo: Guanabara Koogan;2003.p.33-47.

3. Caumo DTM, Ferreira MIDC. Relação entre desvios fonológicos e processamento auditivo. Rev. Soc. Bras. Fonoaudiol. 2009; 14(2): 234-40.

4. Limissuri RC, Befi-Lopes DM. Fonologia e vocabulário na percepção de educadoras sobre comunicação de pré-escolares.Rev. Brasileira de Estudos Pedagógicos. 2009; 90(1): 433-48.

5. Acosta VM, Moreno A, Ramos V, Quintana A, Espino O. Avaliação da linguagem: teoria e prática do processo de avaliação infantil do comportamento linguístico infantil. São Paulo: Santos;2003. p. 279-80.

6. Marchão AJ. (O ensino) Aprendizagem da língua materna na educação de infância: a vivência curricular na creche. Revista Aprender.1999;22(1): 31-7.
7. Delvan J, Ramos MC, Dias MB. A Psicologia escolar/educacional na Educação Infantil: o relato de uma experiência com pais e educadoras. Revista Psicologia - Teoria e Prática. 2002; 4(1):50-60.

8. Lima ABR, Bhering E. Um estudo sobre creches como ambiente de desenvolvimento. Cadernos de Pesqui. 2006;26(129): 573-96.

9. Cachapuz RF, Halpern R. A influência das variáveis ambientais no desenvolvimento da linguagem em uma amostra de crianças. Revista da AMRIGS. 2006; 50(4): 292-301.

10. Papp ACCS, Wertzner HF. O aspecto familial e o transtorno fonológico. Pró-Fono Revista de Atualização Científica. 2006;18(2):151-60.

11. Cavalheiro LG, Keske-Soares M. Prevalência do desvio fonológico em crianças de 4 a 6 anos de idade.[Dissertação de mestrado].Santa Maria (RS): Universidade Federal de Santa Maria; 2007.

12. Pagliarin KC, Brancalioni AR, Keske-Soares M, Souza APR. Relação entre gravidade do desvio fonológico e fatores familiares. Rev. CEFAC [serial on the Internet]. [cited 2011 Aug 22]. Available from: http://www.scielo.br/scielo.php?script=sci_artt ext\&pid=S151618462010005000066\&lng=en. In press 2010. Epub June 25, 2010. doi: 10.1590/ S1516-18462010005000066. 
13. Goulart BNG, Chiari BM. Prevalência de desordens de fala em escolares e fatores associados. Rev. Saúde Pública [online]. 2007; 41(5): 726-31.

14. Casarim MT, Keske-Soares M, Mota HB. Estudo dos desvios de fala em pré-escolares de escolas públicas estaduais de Santa Maria-RS. [Dissertação de Mestrado], Santa Maria(RS):Programa de pós-graduação em Distúrbios da Comunicação; 2006.

15. Vitor RM, Martin CC. Desenvolvimento fonológico de crianças pré-escolares da Região Noroeste de Belo Horizonte. Psicologia em Revista. 2007;13(2):383-98.

16. Ferrante C, Borsel JV, Pereira MMB. Aquisição fonológica de crianças de classe sócio econômica alta. Rev. CEFAC.2008; 10(4):452-60.

17. Ferrante C, Borsel JV, Pereira MMB. Análise dos processos fonológicos em crianças com desenvolvimento fonológico normal. Rev. Soc. Bras. Fonoaudiol.2009;14(1):36-40.

18. Hage SRV, Pereira MB. Desempenho de crianças com desenvolvimento típico de linguagem em prova de vocabulário expressivo. Rev. CEVAC. 2006; 8(1): 419-28.

19. Maria-Mengela MRSM, Linhares MBM. Fatores de risco para problemas do desenvolvimento infantil. Rev Latino-am Enfermagem. 2007; 15(1): 837-42.

20. Isotani SM, Azevedo MF, Chiari BM, Perissinoto $\mathrm{J}$. Linguagem expressiva de crianças nascidas pré-termo e termo aos dois anos de idade. Pró-fono. 2009; 21(2):155-9.

21. Hart SA, Petrill SA, De Thorne SR, DeaterDeckard K, Thompson LA, Schatschneider C et al . Environmental influences on the longitudinal covariance of expressive vocabulary: measuring the home literacy environment in a genetically sensitive design. J Child Psychol Psychiatry. 2009; 50(8): 911-9.

22. Rezende MA, Beteli VC, Santos JLF. Avaliação de habilidades de linguagem e pessoal-sociais pelo Teste de Denver II em instituições de educação infantil. Acta paul. Enferm. 2005; 18(1): 56-63.

http://dx.doi.org/10.1590/S1516-18462011005000139 RECEBIDO EM: 01/03/2011

ACEITO EM: 06/06/2011

Endereço para correspondência:

Stela Maris Aguiar Lemos

Av. Alfredo Balena, ํo 190, Santa Efigênia

Belo Horizonte - Minas Gerais

E-mail: lemos.stela@gmail.com
23. Trivellato-Ferreira MC, Marturano EM. Recursos da Criança, da Família e da Escola Predizem Competência na Transição da $1^{\text {a }}$ Série. Interamerican Journal of Psychology. 2008; 42(3):549-58.

24. Biscegli TS, Polis LB, Santos LM, Vicentin M. Avaliação do estado nutricional e do desenvolvimento neuropsicomotor em crianças freqüentadoras de creche. Rev. paul. Pediatr. 2007;25(4):337-42.

25. Rezende MA, Costa OS, Pontes PB. Triagem de desenvolvimento neuropsicomotor em instituições de educação infantil segundo o teste de Denver II. Esc. Anna Nery Rev. Enferm. 2005;9(3):348-55.

26. Schonhaut $B$, Maggiolo ML, Herrera ME, Acevedo KG, García ME. Lenguaje e inteligencia de preescolares: análisis de su relación y factores asociados. Rev. chil. Pediatr. 2008;79(6):600-6.

27. Adrés ML, Urquijo S, Garcia-Sedeño M. Contexto alfabetizador familiar: relaciones con la adquisición de habilidades prelectoras y desempeño lector. European Journal of Education and Psychology. 2010; 3(1):129-40.

28. Andrade AS, Santos DN, Bastos AC, Pedromônico MRM, Almeida-Filho N, Barreto ML. Ambiente familiar e desenvolvimento cognitivo infantil: uma abordagem epidemiológica. Rev. saúde pública. 2005; 39(4):606-11.

29. Basílio CS, Puccini RF, Silva EMK, Pedromônico MRM. Condições de vida e vocabulário receptivo em crianças de dois a cinco anos. Rev. saúde. 2005;39(5):725-30.

30. Athayde ML, Mota HB, Mezzomo CL. Vocabulário expressivo de crianças com desenvolvimento fonológico normal e desviante. Pró-fono. 2010; 22(2):145-50.

31. Mota HB, Kaminski TI, Nepomuceno MRF, Athayde ML. Alterações no vocabulário expressivo de crianças com desvio fonológico. Rev. Soc. Bras. Fonoaudiol. 2009; 14(1): 41-7.

32. Athayde ML, Carvalho Q, Mota HB. Vocabulário expressivo de crianças com diferentes níveis de gravidade de desvio fonológico. Rev. CEFAC. 2009; 11(2):161-8.

33. Brancalioni AR, Marini C, Cavalheiro LG, Keske-Soares M. Desempenho em prova de vocabulário de crianças com desvio fonológico e comdesenvolvimentofonológiconormal. Rev.CEFAC [serial on the Internet].[cited 2010 Oct 19]. Available from: http://www.scielo.br/scielo.php?script=sci arttext\&pid=S151618462010005000 11\&lng=en. In press 2010. Epub Apr 02, 2010. doi: 10.1590/ S1516 18462010005000011. 